\title{
Participatory Model Construction and Model Use in Natural Resource Management: a Framework for Reflection
}

\author{
Pieter W. G. Bots · C. Els van Daalen
}

Published online: 15 October 2008

(C) The Author(s) 2008. This article is published with open access at Springerlink.com

\begin{abstract}
In this article we propose a framework which can assist analysts in their reflection on the requirements for a participatory modelling exercise in natural resource management. Firstly, we distinguish different types of formal models which may be developed, ranging from models that focus on (bio)physical mechanisms to models which also include the actors involved in the utilisation of the resource and the social mechanisms that co-determine actor behaviour. Secondly, we consider what different modes of stakeholder participation entail for model construction and use. Finally, we propose six different purposes for a modelling exercise (clarify arguments and values, research and analyse, design and recommend, provide strategic advice, mediate, and democratise), and highlight conditions that affect the appropriateness of stakeholder participation for each purpose. The framework does not provide a straightforward recipe for the selection of participatory modelling methods, but we expect that the systematic reflection it affords will help analysts to make appropriate choices while designing a modelling exercise.
\end{abstract}

Keywords Natural resource management · Formal models - Participatory methods · Model typology $\cdot$ Stakeholders

\section{Introduction}

Decision making processes in the context of natural resource management (NRM) frequently involve the use of models that provide computation and visualisation capabilities to support the design and evaluation of alternative NRM policies. Traditionally, these models are constructed by experts who are much more detached from the decision making process than the actors who have a stake in the NRM issue that is decided upon. By

P. W. G. Bots · C. E. van Daalen (凶)

Faculty of Technology, Policy and Management, Delft University of Technology,

P.O. Box 5015, 2600 GA Delft, The Netherlands

e-mail: c.vandaalen@tudelft.nl

P. W. G. Bots

Montpellier Regional Center, Cemagref, BP 5095, 34033 Montpellier cedex 1, France 
contrast, participatory modelling approaches, such as group model building using System Dynamics (Richardson and Andersen 1995; Van den Belt 2004) and 'Companion Modelling' using multi-agent simulation (Bousquet et al. 1999), rely on stakeholder participation not only in the use of the model, but also in its construction.

As the application of participatory modelling methods begins to proliferate, the question when which method is appropriate becomes pertinent. This question is difficult to answer: the terms 'model' and 'method' are very generic, and appropriateness is relative to the purpose of the method and the context in which it is applied. Therefore, instead of providing an answer, we propose a conceptual framework that can support analysts in their reflection on the appropriateness of stakeholder participation in the construction and/or use of models in the context of NRM.

We will develop this conceptual framework as follows. We begin by explaining how we see a model and what we mean by a modelling exercise in the context of NRM. We then focus on the requirements analysis for a modelling exercise because in this step we expect the analyst to decide which NRM model type and which stakeholder participation mode are most appropriate in view of the purpose of the modelling exercise. To support this decision, we propose five NRM model subtypes, four modes of stakeholder participation, six different purposes for construction and/or using models, and a grid and guideline for reflection that provide the analyst a heuristic for finding appropriate combinations.

\section{Modelling Concepts}

Within our conceptual framework, a model is a representation of some referent object that can yield the answer to a question about this referent object more efficiently than the referent object itself (Rothenberg 1989). This general definition includes all types of models used for inquiry, including scale models, mental models, and symbolic models. We will focus on 'executable' models. This does not mean that the model has to be quantitative; it may also consist of a causal diagram which is analysed, or of a protocol for a gaming simulation, which is executed.

We define a modelling exercise as a purposeful activity of constructing and/or using a model in which stakeholders may be involved. By 'purposeful' we mean that the analyst carries out a requirements analysis which leads to what we call a 'model definition': a specification of the intended purpose/function of the modelling exercise (including the questions the model should be able to answer), the anticipated utilisation of the results, the model type, the participation mode and the modelling method/software platform. Thus, the choices made during the requirements analysis will largely determine the way in which the modelling exercise is carried out.

The three steps (requirements analysis, model construction and model use) are presented in Fig. 1 as a cycle, because results may give rise to new questions that call for a new modelling exercise, possibly with a different type of model. Although the diagram suggests that one model is developed, a modelling exercise may also involve multiple models, e.g. to represent and subsequently discuss divergent perspectives of stakeholders (Mingers and Rosenhead 2004).

Modelling exercises usually are part of a larger process of (participatory) NRM decision-making. When designing such a process, the analyst must consider which role the model(s) will play in this process. Modelling exercises may be central to the process (e.g. Bousquet et al. 1999; Van den Belt 2004), but they may also play only a minor part in it (e.g. Tippett 2004; Stauffacher et al., this issue). This means that the process may revolve 
Fig. 1 Schematic representation of a modelling exercise

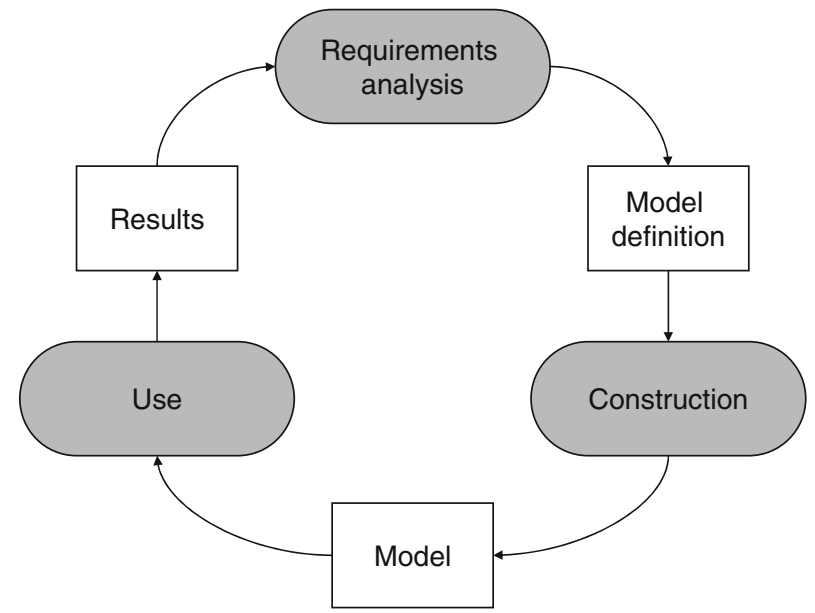

around the model, or that the model may be subservient to the process. The requirements analysis may even reveal that it is better not to construct or use a model to support participatory NRM decision-making. The process design for rural communities by Rist et al. (2006), for example, comprises communicative workshops involving a mix of local and external people that deliberately do not follow structured, cognition-oriented methods such as modelling, to avoid that the external people would impose their mode of thought on the local participants.

In the remainder of this article, we develop a conceptual framework to support the requirements analysis for modelling exercises in the context of NRM. The type of model, the participation of stakeholders in its construction and/or use, and the purpose of the modelling exercise (including the questions the model should be able to answer) will be focal to the discussion, this at the expense of the choice of a particular modelling method and software platform.

\section{Typology of NRM Models}

\section{A Generic NRM Model Type}

We assume that the referent object of a NRM model is the natural resource and its utilisation, and that the questions to be answered by the model are posed by one or more actors who hold a stake in this referent object. This implies that a NRM model should somehow represent the physical aspects of the resource, the social aspects of its utilisation, and the interaction between these aspects. Taking a river as an example, physical aspects could include the geography of the riverbed and its hydrological properties, while social aspects could be related to the utilisation of the river (e.g. for irrigation, navigation and sanitation) and include uses, rules governing those uses, and the social processes through which such rules are developed.

The physical dimension and social dimension are interdependent. The state of the natural resource is influenced by its utilisation and vice versa. Usually this results in tension between different uses, with conflict between different social groups (different user groups, or similar user groups upstream and downstream) as a consequence. 
Figure 2 shows a schematic representation of both dimensions and their interactions. The actors may influence the state of the physical system either directly by acting on the physical system or indirectly by influencing the social system, triggering actions by other actors. Actors take action in response to what outcomes they perceive from the physical system and/or the social system. Although as social entities they are part of the social system, and as biological organisms they are part of the physical system, we have separated the actors from both systems in the diagram because this allows us to identify different types of models that may be developed.

\section{NRM Model Subtypes}

A model which is developed to answer a question related to NRM will consist of one or more parts of the generic NRM model type depicted by Fig. 2. As the three parts (physical system, actors and social system) may or may not be included in a model, $2^{3}=8$ different subtypes of the generic NRM model type can be distinguished as shown in Table 1.

Table 1 shows that five different NRM model subtypes may be distinguished in practice. Taking 'social' to refer to 'the interaction of the individual and the group', we can disregard the two singular cases because it will practically be impossible to represent social mechanisms without also representing actor behaviour. Even when individual actors are not represented, their behaviour will be, or the referent object of the model would not be a social system. For example, the classical equilibrium model of a market (the referent object) that consists of a supply equation $P=\rho+\sigma Q$ and a demand equation $P=\gamma+\delta Q$, and predicts that the market will stabilise at quantity $Q=(\rho-\gamma) /(\delta-\sigma)$, effectively represents the behaviour of producers and consumers, albeit at an aggregate level.

The five model subtypes are shown graphically in Fig. 3. We will first discuss the subtypes which represent only one particular part of the system (PhSM, SADM), then subtypes which combine two parts (IAIM, SoSM), and finally SoPhSM. For each model

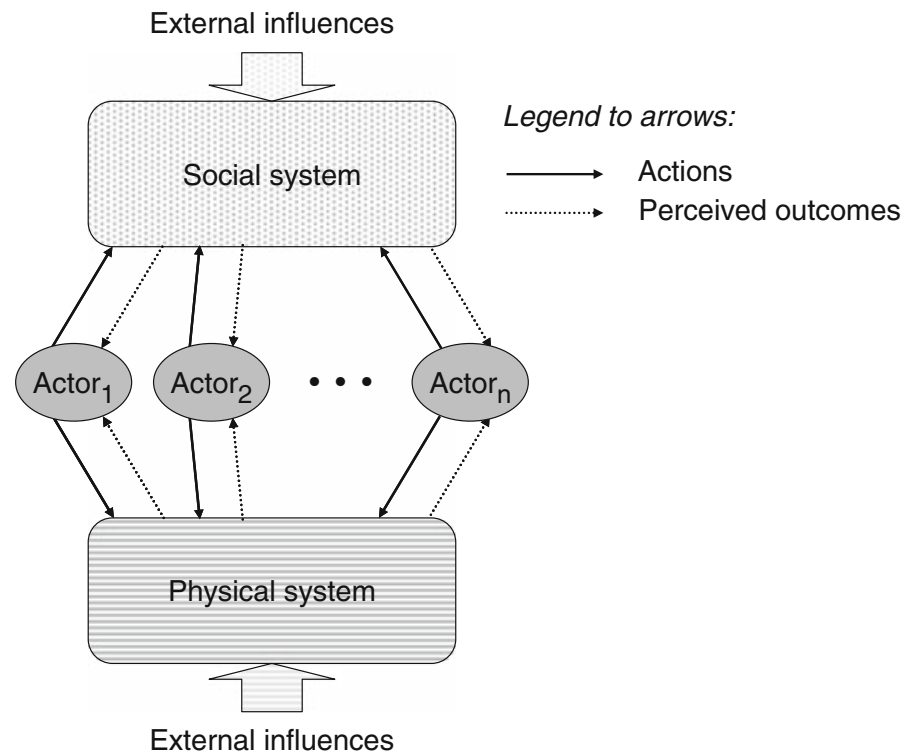

Fig. 2 Generic model type for NRM 
Table 1 NRM model subtypes

\section{P A S NRM model subtype}

$\begin{array}{llll}1 & 1 & 1 & \text { Socio-physical system model (SoPhSM) }\end{array}$

Models of this subtype can represent a complete NRM system: the physical mechanisms of the natural resource, the actors involved in its utilisation, and the social mechanisms that codetermine actor behaviour

$\begin{array}{llll}1 & 1 & 0 & \text { Individual actor impact model (IAIM) }\end{array}$

Models of this subtype can represent how individual actors influence the physical system through their decisions and actions, but do not take into account social mechanisms among actors

$\begin{array}{llll}1 & 0 & 1 & \text { (singular case of SoPhSM) }\end{array}$

$1 \quad 0 \quad 0 \quad$ Physical system model (PhSM)

Models of this subtype can represent the structure and dynamics of the physical, biological and ecological characteristics of the resource, but disregard its utilisation

$\begin{array}{llll}0 & 1 & 1 & \text { Social system model (SoSM) }\end{array}$

Models of this subtype can represent the structure and dynamics of the social space (institutional context and 'policy arena') in relation to actor behaviour, but do not take into account how this behaviour affects the physical aspects of the natural resource

$\begin{array}{llll}0 & 1 & 0 & \text { Single actor decision model (SADM) }\end{array}$

Models of this subtype can represent the relation between the preference structure of an individual actor and alternative NRM measures. They model how actor choices follow from their perceptions; they disregard the structure and dynamics of the physical and social system

$\begin{array}{llll}0 & 0 & 1 & \text { (singular case of SoSM) }\end{array}$

$\begin{array}{llll}0 & 0 & 0 & \text { (no NRM model) }\end{array}$

None of the aspects of a natural resource and its utilisation is represented

$\mathrm{P}=1$ : physical mechanisms are modelled

$\mathrm{A}=1$ : actors and their behaviour (decisions and subsequent actions) are modelled

$\mathrm{S}=1$ : social mechanisms are modelled
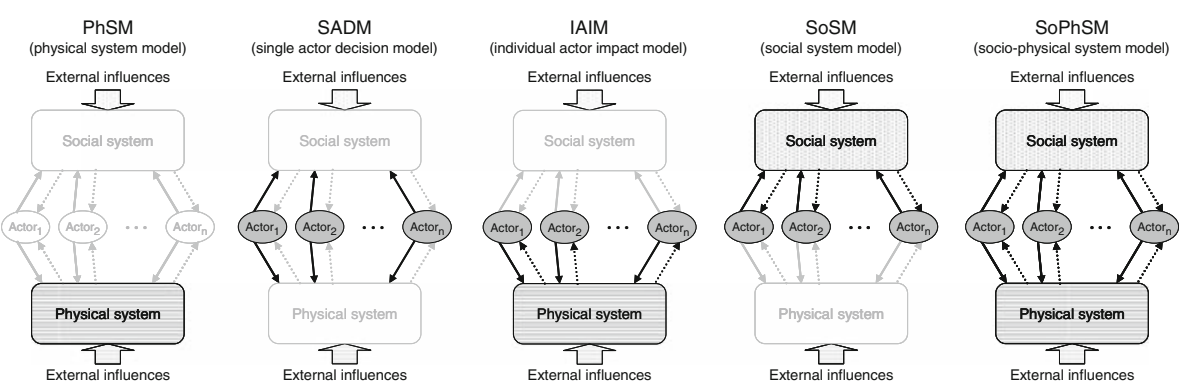

Legend to arrows:

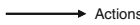

Perceived outcomes

Fig. 3 Typology of NRM models

subtype we will provide one or more examples from the literature to show their relevance for NRM. These examples have been chosen for illustrative purposes only; they by no means provide a complete overview of existing models.

\section{Physical System Model (PhSM)}

A classical example of a NRM model is one that can be used to analyse the consequences of some anthropogenic change in a (bio)physical system, such as building a dam in a river. 
Such a change will have hydrologic and ecological consequences, but it will also have other types of consequences stakeholders will be interested in, such as safety or costs. We call models that can be used for such an analysis physical system models because they consider influences that impact a physical system and resulting consequences.

Brown Gaddis et al. (2007) report on a participatory process in which two models of this subtype (PhSM) have been used to analyse and visualise the impacts of septic tanks, atmospheric deposition, and fertiliser on nitrogen loads in a watershed. One model was a simple dynamic model of a septic tank and leach field system. This model allowed users to input different septic technologies and leach field designs and showed nitrogen leaching over the course of a year and operational costs associated with the input decisions. The other model coupled ecologic and hydrologic process models with GIS software. A simulation run provided visual output showing changes over time in hydrology, water quality, and material flows between cells, as a result of different policy scenarios. In Fig. 3, these policy scenarios would be external influences.

\section{Single-Actor Decision Model (SADM)}

A $\mathrm{PhSM}$ as described above does not represent how stakeholders would react to the outcomes of policies. In certain situations it may be relevant to take this into consideration, for example to anticipate the appreciation (and possibly the actions this provokes) of a local farmer to the construction of a dam. The type of model that represents policies (or merely their outcomes) as external influences, and predicts the reaction (or merely the appreciation) of actors (but not the consequences of these actions, as that would represent other parts of the system as well!) will be termed a single-actor decision model.

A willingness-to-pay model is an example of models of this subtype (SADM). Stevens et al. (2000) describe a case study of the willingness of non-industrial private forest landowners in Massachusetts to pay for ecosystem management activities. They compared two methods of estimating the willingness to pay: contingent valuation and conjoint analysis. The variables included in the econometric models which were estimated are: acres set aside for ecosystem management, increase in wood turtle population as a result of ecosystem management, costs to landowner, income, age and attitude to the environment. Results showed that the landowners would pay some amount even if the benefits do not occur on their own property. The SADM model subtype does not seem to be used very often for NRM, as actor behaviour is usually regarded in connection with the physical and/ or social system in the models of the following subtypes.

\section{Individual Actor Impact Model (IAIM)}

This third model subtype combines a representation of the physical system with a representation of actor behaviour. This allows investigation of the behaviour of the physical system and of the interaction between the individual stakeholders and the physical system, ignoring social mechanisms between actors.

The model of the socio-hydrosystem of the middle of the Hérault valley in France described by Lanini et al. (2004) is an example of an IAIM. Using Matlab, they represented the physical processes as differential equations, and the behaviour of three types of stakeholders (canal management, winegrower and canoe renter) as logical rules, based on a large number of interviews with local stakeholders. As the rules that define the actors' appreciation of the state of the physical system, and their consequent actions, only consider 
physical system state variables (evaporation, rainfall, surface water levels, soil type and water saturation), the model does not represent any form of social interaction.

\section{Social System Model (SoSM)}

Models of this subtype represent the structure and dynamics of the social space or 'policy arena' in which the actors who hold a stake in the resource interact. The goals and preferences of actors become inputs for the model, which represents the interaction between the actors in a way that social behaviour can be inferred (for example using game theory or expected utility theory). Thus, economic models that represent markets and sectors are SoSM. When the interaction possibilities are inputs, a SoSM could also be used to test what would happen if two parties were to negotiate using different sets of rules. In general, models that represent the perceptions and relative positions of different actors (Hermans 2005) also are SoSM.

Prell et al. (this issue) report on a social network analysis aimed at quantifying the social networks that exist between and within different groups who are stakeholder in the management of a natural park in the north of England. Using a structured questionnaire, they collected data on who interacted with whom (and how often), and who perceived whom to hold similar views as their own, and then represented this data as a quantified graph with the stakeholders as nodes. This representation afforded a range of analyses, such as identification of social cliques, and of stakeholders who may act as a liaison between disparate groups.

\section{Socio-Physical System Model (SoPhSM)}

It is also possible to represent a complete NRM system (the physical system, the interaction between the actors, and the way the physical system is influenced by the actors, cf. Fig. 2) in a single model. SoPhSM tend to consist of different sub-models, because they are a combination of IAIM and SoSM, which each have their own appropriate modelling methodologies.

A first example of an SoPhSM (albeit with limited representation of social interactions, the focus being on the physical and individual actor parts of the system) is the naturalhuman system model of land use in a region of north central Texas described by Monticino et al. (2007). The natural system part of this model comprises a land-cover transition model, a hydrological model and a wildlife habitat model. The social system part of the model includes four classes of agents: landowner agents, developer agents, homeowner agents and government agents. Decisions made by one agent will influence a next agent: a landowner may, for example, decide to sell land, which will then influence the actions by a developer agent. The sequence of interactions has been predefined, and the agents make decisions based on multi-attribute utility functions. A formal conjoint analysis was carried out to develop the functions for the homeowners, and for the other agents this was developed from focus group sessions.

The analysis by Lehtonen et al. (2007) of the impacts of different agricultural policies on agricultural production and nutrient leaching from the agricultural land, combining an economic model and an environmental impact model, provides an example of an SoPhSM with a more elaborate representation of the social system. It also shows that actors need not be represented individually to represent actor behaviour. Their nutrient leaching model represents the physical system as a simulation matrix that considers combinations of 6 soil types, 11 crop types and 9 field slopes. The input to the model consists of the percentages 
of each of these combinations present in the area of investigation, the output of the average annual sums of leached phosphorus and nitrate. The economic model consists of two major parts: an equilibrium model which simulates annual production decisions (including the trading of milk quota) and price changes, and a technology diffusion model which determines sector level investments implying evolution of farm size distribution. The technology diffusion part is dynamic, as the farm investments are assumed to depend on the capital already invested in the technique (i.e. on earlier investments).

Other examples of the use of SoPhSM in NRM are described by Espinasse and Franchesquin (2005) and by Janssen et al. (2000) who include biophysical and socio(economic) subsystems in their models.

Although the given examples do suggest so, not all parts of the model need to be represented by means of a computer model. Actor behaviour and social mechanisms can also be represented by people in a gaming simulation/role playing game (Shubik 1975; Duke and Geurts 2004). A gaming simulation will therefore also be seen as a model (i.e. representation) of (part of) a NRM system. This does not necessarily mean participation by actual stakeholders, however, as the nature of the participants taking part in the game will depend on the purpose of the model. This relates to participation in model use, as will be discussed in more detail in the next section.

\section{Stakeholder Participation in Model Construction and Use}

Traditionally, the process of modelling has been conducted by modellers, i.e. people with training and experience in the analysis and formal representation of systems. Modellers depend on sources of information in order to be able to develop a model for a specific context. In some cases it may suffice to use published information or to carry out empirical observations/measurements. Often, it will also be necessary to elicit knowledge from individuals by, for example, conducting interviews. More recently, model development and use of models involving groups of stakeholders-either homogenous (people sharing the same interests) or heterogeneous (people with different and possibly even opposing interests)- has become commonplace.

When modelling exercises are seen as part of a larger process of decision-making, choices regarding stakeholder involvement in a modelling exercise will largely depend on the level of stakeholder participation that is aspired for the decision-making process. The 'Ladder of citizen participation' proposed by Arnstein (1969) with its eight rungs from manipulation to citizen's control has inspired many authors to propose similar typologies of public involvement. Krütli et al. (2006) present an overview of these typologies, and propose to use five levels (information, consultation, active involvement, collaboration and empowerment), but what is more important for the present discussion is their argument that there will be a dynamic pattern of public involvement over the course of a participatory process, and that the level of public involvement depends on the phase and the objectives of the project. This supports our idea that the analyst who designs a modelling exercise should deliberate on whom to involve when, as well as on how to involve them, considering the goals set for the oncoming phase.

For the 'how' decision, the literature (Rowe and Frewer 2000; OECD 2004) offers a range of formal stakeholder participation techniques (e.g. consensus conferences and focus groups) and criteria for selecting those most appropriate. The decision on whom to involve at the level of individual stakeholders may be informed by techniques for actor network analysis (Hermans 2005) and social network analysis (Prell et al., this issue). In the 
remainder of this section we will develop more general options for the 'whom' decision: should stakeholders be involved individually in development and/or use of a model, or as a group? Which of these options is most appropriate will depend on the purpose of the modelling exercise- a crucial aspect that we will discuss in detail in section "Appropriateness of Participation in NRM Modelling Exercises".

We propose four participation modes which we will refer to as NOP (no participation), IND (individual stakeholders are involved separately), HOM (the group of stakeholders that is involved is homogeneous in the sense that they have similar interests and problem perceptions) and HET (the group of stakeholders that is involved is heterogeneous in the sense that they have divergent, and possibly conflicting, interests and problem perceptions). The most important difference between individual participation (IND) and group participation (HOM and HET) is that with group participation in model construction and/or use social learning (Pahl-Wostl 2002a, b) can also take place directly as members of the group interact during the modelling exercise. The type of social learning will be different when the interaction takes place within a group of homogeneous stakeholders than when the interaction takes place within a group of heterogeneous stakeholders (Beers et al. 2006).

Brown Gaddis et al. (2007, p. 621) mention that there are "many stages in the process in which stakeholders can participate including model development, data collection, model assumptions, scenario development, interpretation of results and development of policy alternatives based on model results". The appropriate participation mode may vary for different stages of a modelling exercise. As there are many different modelling methods, each with their own sequence of steps, we limit ourselves to the basic distinction between model construction and model use, with sub-activities inspired by what Gottschick (2005) terms ex ante, in continuum and ex post participation. Within model construction, it is possible that stakeholders provide information for the modeller to make the model, and also that they actually make modelling decisions. Within model use, stakeholders may be involved in defining model inputs (scenarios and/or policies), and in the actual use of the model, discussing the outputs that result from these inputs. We distinguish between these four activities (inform model construction, make modelling decisions, provide inputs for model use, and use computer model) because the stakeholders involved in one phase need not necessarily be the same as those involved in another phase. To these we add a fifth activity (act in gaming simulation) to also cover the special case where participants as players in a gaming simulation are 'part of the model' when it is used.

For each of the four activities (or five in case of a gaming simulation), the analyst can choose a participation mode. For example, information for model construction may be gathered by sending a questionnaire to individuals (IND) or in a workshop with heterogeneous stakeholders (HET). Constructing a model may, for example, be carried out by the modellers themselves (NOP) or by using group model building (HOM or HET). Providing input to a model may be, for example, be carried out by developing scenarios in a homogeneous group (HOM) or based on the literature without involving any stakeholders (NOP). Model use could, for example, be done by showing individual stakeholders the results (IND), or by discussing model results in workshop with a heterogeneous group (HET).

The four participation modes can be combined with the five activities to form a table. Starting with an empty table, the analyst can, for each activity, record the pros and cons of each participation mode, and then decide which mode is most appropriate. Table 2 shows the structure of such a table, but instead of the effects of different combinations for a particular modelling exercise, its cells contain references to articles that report examples of 
Table 2 Participation modes for model construction and model use activities

\begin{tabular}{|c|c|c|c|c|c|}
\hline \multirow[t]{2}{*}{ Mode } & \multicolumn{2}{|c|}{ Model construction } & \multicolumn{3}{|l|}{ Model use } \\
\hline & $\begin{array}{l}\text { Inform model } \\
\text { construction }\end{array}$ & $\begin{array}{l}\text { Make modelling } \\
\text { decisions }\end{array}$ & $\begin{array}{l}\text { Provide inputs } \\
\text { for model use }\end{array}$ & $\begin{array}{l}\text { Use computer } \\
\text { model }\end{array}$ & $\begin{array}{l}\text { Act in gaming } \\
\text { simulation }\end{array}$ \\
\hline NOP & & & & & $\begin{array}{l}\text { Students used as } \\
\text { players by Kuit } \\
\text { et al. (2005) }\end{array}$ \\
\hline IND & $\begin{array}{l}\text { Molin (2005); } \\
\text { Stauffacher } \\
\text { (this issue) }\end{array}$ & $\begin{array}{l}\text { Cognitive } \\
\text { mapping-part } \\
\text { of German case } \\
\text { study of Newig } \\
\text { et al. (this issue) }\end{array}$ & & Dudley (2003) & $\begin{array}{l}\text { Sterman (1992); } \\
\text { Maier and } \\
\text { Grossler (2000) }\end{array}$ \\
\hline \multirow[t]{2}{*}{$\mathrm{HOM}$} & $\begin{array}{l}\text { Focus groups of } \\
\text { Monticino } \\
\text { et al. }(2007)\end{array}$ & $\begin{array}{l}\text { Castella et al. } \\
\text { (2005); } \\
\text { Gottschick (this } \\
\text { issue) }\end{array}$ & $\begin{array}{l}\text { Prell et al. } \\
\quad \text { (this issue) }\end{array}$ & $\begin{array}{l}\text { van Daalen } \\
\text { et al. (1998) }\end{array}$ & $\begin{array}{l}\text { Mayer et al. } \\
(2005)\end{array}$ \\
\hline & \multicolumn{5}{|c|}{ Austrian study of Newig et al. (this issue) } \\
\hline HET & & $\begin{array}{l}\text { Van den Belt } \\
\text { (2004) }\end{array}$ & & $\begin{array}{l}\text { Brown Gaddis et al. } \\
\text { (2007); Stauffacher } \\
\text { (this issue); Prell } \\
\text { et al. (this issue) }\end{array}$ & $\begin{array}{l}\text { Etienne et al. } \\
\quad(2003)\end{array}$ \\
\hline & & & Volkery & et al. (this issue) & \\
\hline
\end{tabular}

the corresponding activity/participation mode combination. Like the previous examples, they serve as illustrations; the set is neither complete nor exhaustive.

In the next section we will discuss the way in which the choice of participation mode relates to the particular purpose of a participatory modelling exercise.

\section{Appropriateness of Participation in NRM Modelling Exercises}

Ideally, the requirements analysis for a NRM modelling exercise leads to a model definition that specifies an appropriate combination of NRM model subtype, modelling method, and stakeholder participation mode. The appropriateness of such a combination strongly depends on the purpose of the modelling exercise and, in case of multiple purposes, the relative extent to which each of these purpose is to be achieved.

The framework for understanding and design of policy analyses proposed by Mayer et al. (2004) - derived by analysing exemplary cases in the field of policy analysis, and found to be useful in the context of NRM policy development (Bots and Van Daalen 2007)_-provides six generic purposes to which a modelling exercise may contribute in the context of a participatory decision-making process. By formulating, for each of these purposes, the questions that are addressed, the potential for constructing and using models to find answers to those questions becomes clear. This then allows reflection on the appropriateness of different NRM model subtypes, given the associated methods and possibilities of stakeholder participation in their construction and/or use as identified in the previous sections.

The six purposes are arranged in a hexagon as shown in Fig. 4. As explained by Mayer et al. (2004), the top half of the hexagon is primarily 'object-oriented', focussing on systems, policy measures, and models, whereas the bottom half is 'subject-oriented', 
focussing on people (decision makers, stakeholders, researchers) and their interactions in a policy process. The purposes on the left-hand side of the hexagon stem from more idealistic, Habermasean values, whereas the purposes on the right-hand side stem from more pragmatic, decision-oriented values.

Table 3 provides an overview of how we relate the six purposes of a modelling exercise as shown in the hexagon to the aspects of a NRM system that the modelling exercise can be expected to focus on, the types of questions that the model should help to answer, and the NRM model subtypes that seem appropriate. The relation between purpose and participation mode will be very context-dependent, but the following general reflections may be of help to analysts while drawing up a table like the one we propose in Table 2.

When the purpose is to clarify arguments and values, all stakeholder participation modes may be appropriate: the modeller may perform document analysis only (NOP), interview individual stakeholders (IND), work with homogenous focus groups (HOM), or use Strategic Assumption Surfacing and Testing (Mason and Mitroff 1981) or similar techniques to lead stakeholders to take and defend extreme positions (HET). If the model is developed with little or no stakeholder participation, it may be discussed with stakeholders to share the insights it provides.

When the purpose is to research and analyse, it is crucial for model construction to know what questions will be posed when the model is used. When a model is developed by a scientist without consulting stakeholders (NOP), it may not represent the aspects of the natural resource and/or its utilisation to which the questions pertain. Interaction with stakeholders (individually or in groups) can provide the information the modellers need, while it allows stakeholders to appreciate which questions exceed the state of the art of scientific knowledge. An important constraint is time. Decision-making processes and modelling processes proceed at different speeds: modellers may need months to construct a model capable of answering the questions that stakeholder would like to see answered in days. Stakeholder participation is likely to increase the number and variety of questions and thus to aggravate the problem, although when all stakeholders participate in model construction (HET), they might jointly decide on the priority of questions. Another constraint is that stakeholders must have confidence in the validity of the model. Here, participation is expected to facilitate trust building among different stakeholders, which may enhance confidence in the model and the answers it provides. But participation may be

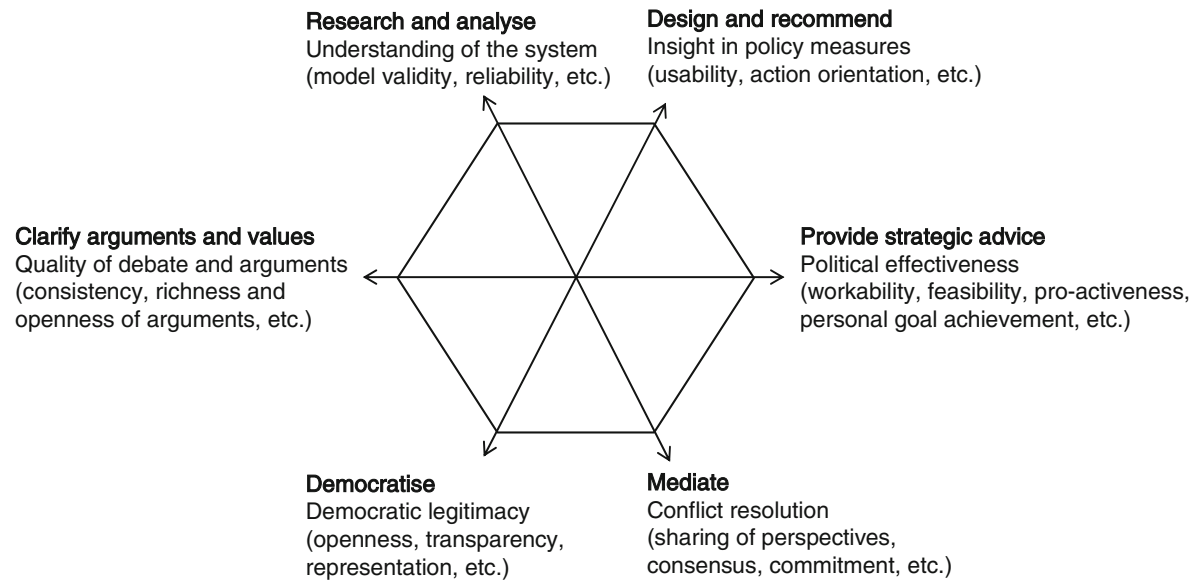

Fig. 4 Purposes of a modelling exercise (after Mayer et al. 2004) 


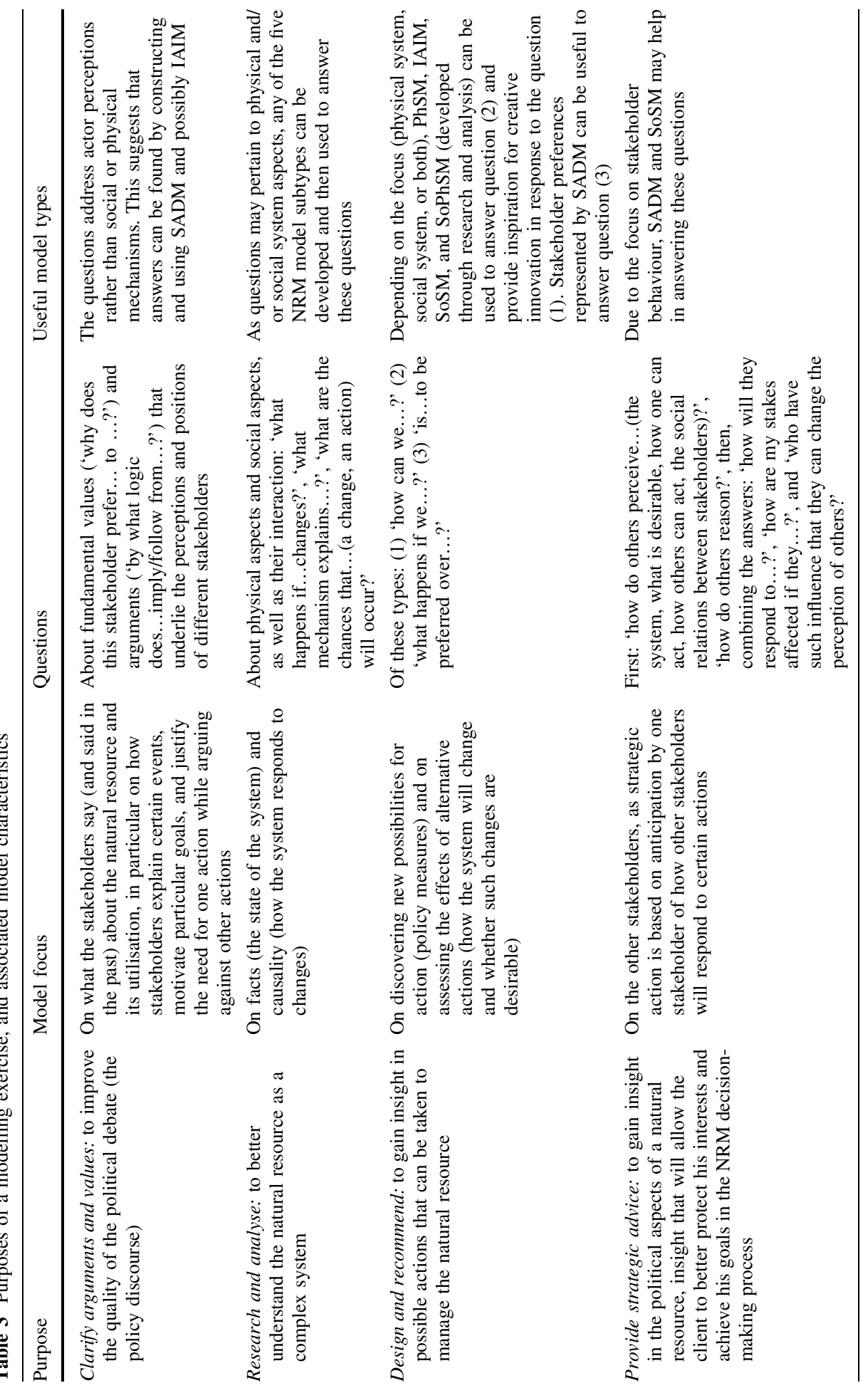




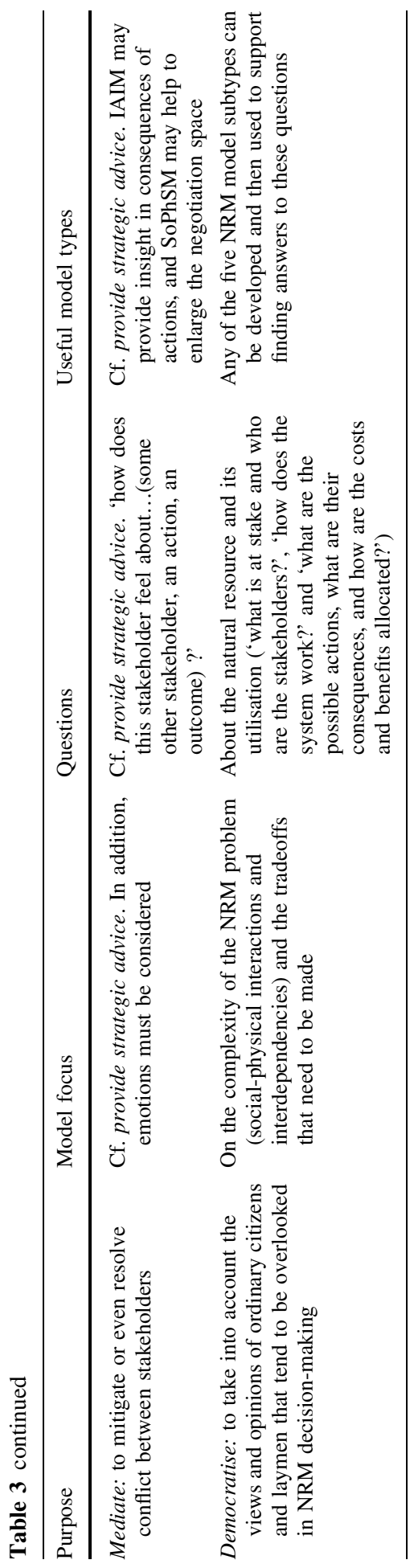


impaired by a third constraint: the cognitive ability of stakeholders. Participatory model construction requires representations that are easy to understand for non-experts, and this may limit the choice of modelling methods.

When the purpose is to design and recommend, the considerations regarding stakeholder participation in model construction and use are similar to when the purpose is to research and analyse. When (participatory) model use leads to novel ideas for action, new 'what if...?' questions arise that may call for a new iteration through the cycle in Fig. 1.

When the purpose is to provide strategic advice, the client for the modelling exercise will typically be one particular stakeholder who wishes to gain a strategic advantage in the NRM decision-making process. This limits the participation modes for model construction and use to IND or HOM. Mode HET implies that the results of the modelling exercise are available to all participants, which would negate the strategic advantage for the client. HOM group participation in model construction and use is conceivable in the group is a subset of the client's 'inner circle' of trusted individuals. In a politically sensitive context, it may even be difficult for a modeller to successfully realise IND participation in model construction, as stakeholders other than the client will be reluctant to reveal their true opinions. By consequence, the validity of the perceptions modelled by SADM and the relations modelled by SoSM may be limited.

When the purpose is to mediate, the construction and use of models can support mediation in different ways. When the conflict is substantive, rather than emotional, a modelling exercise could help to broaden the scope of the social and/or physical system and find acceptable 'package deals' (a set of NRM measures that distributes costs and benefits more evenly). When stakeholders have hostile feelings towards each other, a modelling exercise could help to 'rationalise' the conflict, shifting the focus from the emotional back to the substantive. Some degree of stakeholder participation is indispensable: no matter how much the modeller learns about the conflict, mediation is successful only when the stakeholders who are in conflict change their perception of the situation and/or their feelings towards other stakeholders. When an emotional conflict is such that stakeholders do not want to be in the same room with each other and HET participation is impossible, separate modelling exercises with HOM participation may still be an option. IND participation will in general be acceptable even for severe conflicts. Joint model use may be less confronting than joint model construction, especially when the model represents a NRM situation that is similar but not identical to the situation in which the stakeholders find themselves. It may be appropriate to use a completely fictitious model (drop the ambition of obtaining valid substantive results) to create a 'safe environment' (Duke and Geurts 2004) that allows stakeholders to interact socially (to achieve useful social results).

When the purpose is to democratise, HET participation in model construction and use would seem appropriate. However, the differences in perception between parties may be such that the answers the models provide are difficult to grasp (intellectually) or accept (politically) for certain stakeholders. Model complexity and the need for specialised knowledge may prohibit the use of certain methods. Another caveat is that stakeholders who participate in the construction of a model may come to expect a high utilisation level of the results it produces, which may not be warranted by the way the modelling exercise is embedded in the institutional context of the NRM decision-making process.

The final observation of the preceding paragraph on modelling exercises for democratisation brings to the fore once again that a modelling exercise usually is part of a larger decision-making process, and that the designer of this exercise should take into account the characteristics of this process when deciding on the purpose(s) of the exercise, the NRM 
model subtype, and the stakeholder participation modes. The choice of purpose is strongly related to defining what (and whose) questions the model should help answering. The questions posed co-determine which stakeholders can or should participate in a modelling exercise. The modelling exercise is expected to have some impact on the decision-making process it is part of, raising new issues, involving new stakeholders, and possibly changing some people's opinion on what level of stakeholder participation should be aspired. Thus, a participatory decision-making process can include a series of iterations through the cycle in Fig. 1, where for each iteration the context is likely to have changed such that the requirements analysis leads to a different model definition.

\section{Framework Application}

The conceptual framework developed in the preceding sections is intended to support the requirements analysis for modelling exercises in the context of NRM decision-making. As such, it is a design aid, rather than a tool for post hoc analysis. Moreover, post hoc analysis of a modelling exercise will be difficult if one does not have full information about this exercise. By consequence, the following examples, based on case studies reported elsewhere in this issue, merely illustrate how the modelling exercises were embedded in participatory decision-making processes.

\section{Research and Analyse}

In the Austrian case reported by Newig et al. (this issue), the objective was to evaluate how the EU's Common Agricultural Policy reform affects the quality of life of women living in agrarian households. An agent-based model of type SoPhSM was developed and used in a participatory process. The actors in the model influence land use through their actions, driven by decisions (notably on production, to lease out land, or to take a lease on some other farmer's land) based on their own situation (notably available human resources) and exogenous factors (notably market prices, milk quota and the EU Common Agricultural Policy). The social interaction between actors in this model takes place via a 'market place' where farmers trade their leaseholds. The participatory process included a series of focus group meetings with women (HOM), and workshops with representatives of stakeholders and decision makers (HET). The agent-based model was constructed on the basis of information obtained from interviews (IND) and the outcomes of the first meeting/workshop. During the second meeting/workshop, the design and initial output of the model were discussed. The third meeting/workshop focused on developing storyline scenarios and during the last meetings/workshops the model was used to show the impact of different actions under different policy conditions.

\section{Democratise/Research and Analyse}

The PRELUDE case study described by Volkery et al. (this issue) is an example of a combination of democratise and research and analyse. Land use scenarios for the EU-25 plus Norway and Switzerland were developed during a participatory process involving 30 stakeholders who met three times for a three-day event. The stakeholder panel (HET) consisted of participants from across Europe with a diversity of backgrounds (e.g. policy makers, academic researchers, representatives of interest groups, land-use modellers). A land use/cover change model was used to support the scenarios with quantitative and 
spatially explicit data. This land use/cover change model is an SoPhSM which incorporates physical processes and socio-economic activities. The project was not aimed at model construction, but an existing model was used in the participatory process of scenario development. The scenario development was based on the 'story-and-simulation' approach, where the stakeholders develop qualitative storylines which are formalised and quantified by models.

\section{Clarify Arguments and Values/Mediate/Design and Recommend}

During the first phase of the German case study described by Newig et al. (this issue), group model building was used as a method for clarifying values and arguments. The case concerned a German river catchment with serious ecological threats caused by nitrogen pollution. An actor platform consisting of 14 representatives was established with the objective of discussing measures for the reduction of diffuse pollution. A cognitive map of the perspective of each actor was developed on the basis of a personal interview (IND). The interviewees were asked for measures (e.g. legal rules, changed consumer behaviour) that could lead to nitrate reductions and for the causal relations leading from the measures to water quality. The participants were thus constructing an IAIM by modelling individual stakeholder behaviour and the impact on the physical system. During the participatory process these perspectives were merged into one synthesis causal diagram (i.e. mediate). As part of this process the implicit beliefs of the stakeholders were made explicit. The results of this process were then used in subsequent sessions of the actor platform (HET), which were then geared at participatively selecting measures to mitigate groundwater pollution in the region (i.e. design and recommend).

These three examples show that different purposes may be aimed for simultaneously in one phase of a participatory decision-making process, or separately in a sequence of singlepurpose (or at least less multi-purpose) activities. When combining different purposes, the designer should be aware that different purposes relate to different values, and that a modelling exercise may require value tradeoffs (e.g. validity versus understandability).

As stated above, the primary use of the framework is for reflection before starting a modelling exercise. With this intention it may be used in the following way:

- Scan the context of the decision process. To consider the broader context within which the modelling exercise will play a role, a number of questions pertaining to the decision situation should be addressed, such as, what is the objective of the participatory process, who is the client/process sponsor, what is the phase of the decision process, who are the stakeholders [e.g. carry out a pre-process actor analysis (Hermans 2005; Sauer, this issue)], what is the desired level of stakeholder participation, what could a modelling exercise contribute to the process?

- Use the hexagon to determine which purposes are appropriate for the modelling exercise and formulate the questions that are to be addressed in the modelling exercise.

- Select the type(s) of model that is/are relevant for answering the modelling questions in this specific context using the typology of model subtypes.

- For each of the purposes that have been selected, look at each of the five modelling activities (shown horizontally in Table 2) and determine to which extent the activity will have to contribute to "object-oriented values" and which of the stakeholders have relevant knowledge/information for that activity. This will provide a list of content related stakeholders. Do the same for the "subject-oriented values" and determine 
which of the stakeholders are important to include for that specific purpose for that specific activity in the modelling exercise for process reasons (process related stakeholders). Analyse the full set of stakeholders for heterogeneity/homogeneity. If the set is heterogeneous, distinguish the different parties (homogeneous clusters).

- For each of the purposes identified from the hexagon, draw up a table showing the five modelling activities against the four participations modes to determine which of the participation modes would ideally be used for which of the activities, including which stakeholders are to be involved.

- Compare the resulting tables and look for differences and similarities. Indicate opportunities (synergy between the different values), but also indicate constraints, such as social constraints (stakeholder conflicts) or managerial constraints (time and budget).

- Separate (different exercises with different stakeholders) and combine (synergy).

\section{Conclusion}

In this article we have proposed a conceptual framework that can support analysts during the requirements analysis that we consider to be an essential first step in a NRM modelling exercise. The framework highlights important decisions which the analyst has to make with respect to three aspects: purpose of the modelling exercise, model type and method, and participation mode. To assist the analyst in making a choice, we have drawn up a typology for each of these aspects.

The first typology relates to the possible purposes of a modelling exercise. We have proposed six different purposes: research and analyse, design and recommend, provide strategic advice, mediate, democratise, and clarify arguments and values. The choice of purpose is strongly related to defining what (and whose) questions the model should help in answering. When combining different purposes, the analyst should be aware that a modelling exercise may require value tradeoffs (e.g. validity versus understandability).

The second part of the framework is a typology of NRM models, based on a generic model type that leads the analyst to identify the physical aspects of the resource, the social aspects of its utilisation, and the interaction between these aspects. From this generic model type we have derived five subtypes of models that differ in the extent and way in which they represent the physical and social dimension. The purpose of a modelling exercise together with the context of the decision situation provide input for the choice of the type of model which is to be developed.

The final part of the framework focuses on the relationship between participation modes and activities in model construction and model use. This allows to analyst to make a conscious choice regarding the relevant participation mode or modes for different activities within model construction and use.

The proposed framework disregards the substantive particulars of the NRM policy context; it does not provide criteria for involving individual stakeholders, nor for selecting specific participation methods. Although it does provide arguments against using certain model types or participation modes for certain purposes, it is not intended to be prescriptive. We claim that it contributes to the practice of participatory modelling by putting forward some important decisions that designers of modelling exercises all too often make implicitly, and by providing a structure that invites these designers to systematically consider alternative options, and to make explicit what tradeoffs led them to their choices. 
Due to the lack of powerful theories about such complex social phenomena as participatory decision-making processes, these design choices still remain exploratory and may not produce the anticipated results. Nevertheless, we believe that the more structured and transparent the designs, the better they afford to draw lessons about the relation between design choices and outcomes, and that this allows science in this field to progress.

Open Access This article is distributed under the terms of the Creative Commons Attribution Noncommercial License which permits any noncommercial use, distribution, and reproduction in any medium, provided the original author(s) and source are credited.

\section{References}

Arnstein SR (1969) A ladder of citizen participation. J Am Inst Plan 30:216-224

Beers PJ, Boshuizen HPA, Kirschner PA, Gijselaers WH (2006) Common ground, complex problems and decision making. Group Decis Negot 15:529-556

Bots PWG, Van Daalen CE (2007) Functional design of games to support NRM policy development. Simul Gaming 38(4):512-532

Bousquet F, Barreteau O, Le Page C, Mullon C, Weber J (1999) An environmental modelling approach. The use of multi-agent simulations. In: Blasco F, Weill A (eds) Advances in environmental and ecological modeling. Elsevier, France

Brown Gaddis EJ, Vladich H, Voinov A (2007) Participatory modeling and the dilemma of diffuse nitrogen management in a residential watershed. Environ Model Softw 22:619-629

Castella JC, Trung TN, Boissau S (2005) Participatory simulation of land-use changes in the northern mountains of Vietnam: the combined use of an agent-based model, a role-playing game, and a geographic information system. Ecol Soc 10(1):27. URL: http://www.ecologyandsociety.org/vol10/ iss $1 / \operatorname{art} 27 /$

Dudley RG (2003) Modeling the effects of a log export ban in Indonesia. Syst Dyn Rev 20(2):99-116

Duke RD, Geurts JLA (2004) Policy games for strategic management: pathways into the unknown. Dutch University Press, Amsterdam

Espinasse B, Franchesquin N (2005) Multiagent modeling and simulation of hydraulic management of the Camargue. Simulation 81(3):201-221

Etienne M, Le Page C, Cohen M (2003) A step-by-step approach to building land management scenarios based on multiple viewpoints on multi-agent system simulations. J Artif Soc Soc Simul 6(2). URL: http://jass.soc.surrey.ac.uk/6/2/2.html

Gottschick M (2005) Participatory material flow analysis for production chains. Abstracts 3rd international conference of the international society for industrial ecology, Stockholm, pp 230-232

Gottschick M (2007) On the way from scenario writing to group model building? Methodological aspects of participatory sustainable impact assessment (this issue)

Hermans L (2005) Actor analysis for water resources management: putting the promise into practice. Eburon, Delft

Janssen MA, Walker BH, Langridge J, Abel N (2000) An adaptive agent model for analysing co-evolution of management and policies in a complex rangeland system. Ecol Model 131(2-3):249-268

Krütli P, Stauffacher M, Flüeler T, Scholz RW (2006) Public involvement in repository site selection for nuclear waste: towards a mode dynamic view in the decision-making process. Proceedings VALDOR 2006 — values in decisions on risk, Stockholm, pp 96-105

Kuit M, Mayer IS, De Jong M (2005) The INFRASTRATEGO game: an evaluation of strategic behavior and regulatory regimes in a liberalizing electricity market. Simul Gaming 36(1):58-74

Lanini S, Courtois N, Giraud F, Rinaudo JD (2004) Socio-hydrosystem modelling for integrated waterresources management-the Herault catchment case study, southern France. Environ Model Softw 19:1011-1019

Lehtonen H, Barlund I, Tattari S, Hilden M (2007) Combining dynamic economic analysis and environmental impact modelling: addressing uncertainty and complexity of agricultural development. Environ Model Softw 22:710-718

Maier F, Grossler A (2000) What are we talking about? A taxonomy of computer simulations to support learning. Syst Dyn Rev 16(2):135-148

Mason RO, Mitroff II (1981) Challenging strategic planning assumptions. Wiley, New York 
Mayer IS, Van Daalen CE, Bots PWG (2004) Perspectives on policy analyses: a framework for understanding and design. Int J Tech Pol Manag 4(2):169-191

Mayer IS, van Bueren EM, Bots PWG, van der Voort HG, Seijdel RR (2005) Collaborative decision making for sustainable urban renewal projects: a simulation-gaming approach. Environ Plan B Plan Des 32(3):403-423

Mingers J, Rosenhead J (2004) Problem structuring methods in action. Eur J Oper Res 152:530-554

Molin EJE (2005) A causal analysis of hydrogen acceptance. Transportation Research Board Annual Meeting, $17 \mathrm{p}$

Monticino M, Acevedo M, Callicot B, Cogdill T, Lindquist C (2007) Coupled human and natural systems: a multi-agent-based approach. Environ Model Softw 22:656-663

Newig J, Gaube V, Berkhoff K et al (2007) The role of formalisation, participation and context in the success of public involvement mechanisms in resource management (this issue)

OECD (2004) Stakeholder involvement techniques. Short guide and annotated bibliography. Nuclear Energy Agency No. 5418

Pahl-Wostl C (2002a) Towards sustainability in the water sector-the importance of human actors and processes of social learning. Aquat Sci 64(4):394-411

Pahl-Wostl C (2002b) Participative and stakeholder-based policy design, evaluation and modeling processes. Integr Assess 3(1):3-14

Prell C, Hubacek K, Quinn C, Reed M (2007) 'Who's in the network?' When stakeholders influence data analysis (this issue)

Richardson GP, Andersen DF (1995) Teamwork in group model building. Syst Dyn Rev 11:113-137

Rist S, Chiddambaranathan M, Escobar C, Wiesmann U (2006) "It was hard to come to mutual understanding..."- the multidimensionality of social learning processes concerned with sustainable natural resource use in India, Africa and Latin America. Syst Pract Action Res 19:219-237

Rothenberg J (1989) The nature of modeling. In: Widman L, Loparo K, Nielsen N (eds) Artificial intelligence, simulation, and modeling. Wiley, New York, pp 75-92

Rowe G, Frewer LJ (2000) Public participation methods: a framework for evaluation. Sci Tech Hum Values 25(1):3-29

Sauer A (2007) Conflict pattern analysis-preparing the ground for policy implementation (this issue)

Shubik M (1975) Games for society business and war; towards a theory of gaming. Elsevier, New York

Stauffacher M, Flüeler T, Krütli P, Scholz RW (2007) Systematic and dynamic approach to collaborative landscape planning: a transdisciplinary case study in a Swiss pre-alpine region (this issue)

Sterman JD (1992) Teaching takes off-flight simulators for management education. OR/MS Today, October, pp 40-44

Stevens TH, Belkner R, Dennis D, Kittredge D, Willis C (2000) Comparison of contingent valuation and conjoint analysis in ecosystem management. Ecol Econ 32:63-74

Tippett J (2004) “Think like an ecosystem"-embedding a living system paradigm into participatory planning. Syst Pract Action Res 17(6):603-622

van Daalen CE, Thissen WAH, Berk MM (1998) The Delft process: experiences with a dialogue between policy makers and global modellers. In: Alcamo J, Leemans R, Kreileman E (eds) Global change scenarios of the 21st century: results from the IMAGE 2.1 model. Elsevier, London, pp 267-285

Van den Belt M (2004) Mediated modeling: a system dynamics approach to environmental consensus building. Island Press, Washington DC

Volkery A, Hoogeveen Y, Ribeiro T (2007) Your vision or my model? Lessons from participatory land use scenario development at the European scale (this issue) 